\title{
Parochialism or Self-Consciousness? Internationality in Medical History Journals 1997-2006
}

\author{
HUBERT STEINKE and YVES LANG*
}

\begin{abstract}
Research councils, universities and funding agencies are increasingly asking for tools to measure the quality of research in the humanities. One of their preferred methods is a ranking of journals according to their supposed level of internationality. Our quantitative survey of seventeen major journals of medical history reveals the futility of such an approach. Most journals have a strong national character with a dominance of native language, authors and topics. The most common case is a paper written by a local author in his own language on a national subject regarding the nineteenth or twentieth century. American and British journals are taken notice of internationally but they only rarely mention articles from other history of medicine journals. Continental European journals show a more international review of literature, but are in their turn not noticed globally. Increasing specialisation and fragmentation has changed the role of general medical history journals. They run the risk of losing their function as international platforms of discourse on general and theoretical issues and major trends in historiography, to international collections of papers. Journal editors should therefore force their authors to write a more international report, and authors should be encouraged to submit papers of international interest and from a more general, transnational and methodological point of view.
\end{abstract}

Keywords: Journals; Research Quality; Internationality; Languages; Historiography; Citations

The most obvious characteristics of post-modern historiography are - as Peter Burke argues and as few historians would deny - specialisation and globalisation. ${ }^{1}$ The process of globalisation as an international spread of historiographic methods and trends is generally welcomed; François Bédarida, the secretary-general of the International Committee of Historical Sciences, stated in his address to the 2000 meeting, that 'it tended to

(c) Hubert Steinke and Yves Lang, 2011.

*Hubert Steinke MD, PhD and Yves Lang, MD, Institute for the History of Medicine, University of Bern, Buehlstrasse 26, 3012 Bern, Switzerland. Email: hubert.steinke@mhi.unibe.ch

\footnotetext{
${ }^{1}$ Peter Burke, 'The Web and the Seams: Historiography in an Age of Specialization and Globalization', in Benedikt Stuchtey and Peter Wende (eds), British and German Historiography, 1750-1950. Traditions, Perceptions, and Transfers (Oxford: Oxford University Press, 2000), 401-9.
} 


\section{Hubert Steinke and Yves Lang}

unify the historian's methods, approaches and practices, lines of questioning and scholarly discourse'. ${ }^{2}$ Specialisation, however, is often regarded with mixed feelings. On the one hand, it is considered a threat to such an ideal of a community of historians as it splits it into innumerable sub-communities discussing specialties and minutiae of no relevance to the others. On the other hand, such a fragmentation is embraced by postmodernists as it creates a 'post-paradigmatic' world in which no 'grand' and inherently exclusive or oppressive narrative is able to dominate. ${ }^{3}$

These developments and beliefs apply also to the historiography of medicine, although there are few voices that criticise specialisation and pluralism. Frank Huisman maintains that diversity should be cherished and should lead to a fruitful debate between different methodological positions and historical genres. ${ }^{4}$ John Burnham argues that although many articles are focused on a specific, even narrow topic, they make - or allow us to make - connections to much of the rest of medical history. ${ }^{5}$ A novice might be surprised by the richness and variety of the discipline: studying Wolfgang Eckart's and Robert Jütte's introduction to medical historiography, he will find a presentation of nine different well-established methodological approaches (history of ideas, body history etc.) and eight border disciplines (e.g. medical ethics). ${ }^{6}$ Today's historians of medicine seem to be pleased with this diversity and - increasingly interested in historiography - are discussing the development and potentialities of the various methods and sub-disciplines. ${ }^{7}$

Despite this increased interest in historiography, reflection on the other main characteristic, internationality, is scarce. Some authors focus on the development and status of medical history in single countries (especially Germany, France, Britain and the USA) ${ }^{8}$, others make out national traditions with regard to the formulation of certain historiographical concepts, ${ }^{9}$ but there is no proper discussion of internationality, that is, to what extent there is an international exchange and adjustment of methods and topics, and whether such an exchange should be intensified or not. The general assumption that seems to prevail is that in our postmodern world everything is global and that all new trends and insights are spread and absorbed globally. As a recent paper by Olga

\footnotetext{
${ }^{2}$ Karl Dietrich Erdmann, Toward a Global Community of Historians: The International Historical Congresses and the International Committee of Historical Sciences, 1898-2000, Jürgen Kocka (ed.), (New York: Berghahn, 2005), 347.

${ }^{3}$ Peter Lambert and Phillip R. Schofield (eds), Making History: An Introduction to the History and Practices of a Discipline (London: Routledge, 2004), 63.

${ }^{4}$ Frank Huisman, 'The Dialectics of Understanding: On Genres and the Use of Debate in Medical History', History and Philosophy of the Life Sciences, 27 (2005), 13-40: 37.

${ }^{5}$ John Burnham, What is Medical History? (Cambridge, MA: Polity, 2005), 136.

${ }^{6}$ Wolfgang U. Eckart and Robert Jütte, Medizingeschichte: Eine Einführung (Stuttgart: UTB, 2007).

${ }^{7}$ For example, Norbert Paul and Thomas Schlich (eds), Medizingeschichte: Aufgaben, Probleme, Perspektiven, (Frankfurt am Main: Campus, 1998);
}

Frank Huisman and John Harley Warner (eds), Locating Medical History: The Stories and Their Meanings (Baltimore, MD: Johns Hopkins University Press, 2004); Stefan Schulz, Klaus Steigleder, Heiner Fangerau and Norbert Paul (eds), Geschichte, Theorie und Ethik der Medizin: Eine Einführung, (Frankfurt am Main: Suhrkamp, 2006).

${ }^{8}$ For example, Roy Porter, 'The Historiography of Medicine in the United Kingdom', in Huisman and Warner, op. cit. (note 7), 194-208, and Martin Dinges, 'Social History of Medicine in Germany and France in the Late Twentieth Century: From the History of Medicine Toward a History of Health', in idem, 209-36.

${ }^{9}$ For example, Francisca Loetz, 'Medikalisierung in Frankreich, Grossbritannien und Deutschland, 1750-1850: Ansätze, Ergebnisse und Perspektiven der Forschung', in Wolfgang U. Eckart and Robert Jütte (eds), Das europäische Gesundheitssystem: Gemeinsamkeiten und Unterschiede in historischer Perspektive, (Stuttgart: Franz Steiner, 1994), 123-61. 


\title{
Parochialism or Self-Consciousness?
}

Amsterdamska and Anja Hiddinga suggests, such a belief might be deceptive. ${ }^{10}$ Their analysis of the four leading American and British journals of medical history (Bulletin of the History of Medicine, Journal of the History of Medicine, Medical History, Social History of Medicine) shows a relatively small overlap of the most highly cited historians between these journals and - strikingly - this seems to be due to a national bias. Judging from Amsterdamka's and Hiddinga's study, medical history appears to have no strong core set of internationally shared discourses - much in contrast to, for example, the social studies of science.

Our aim is to provide some further material in order to promote reflection on the internationality of medical history. We have performed a quantitative analysis of medical history journals because any other approach, such as the analysis of monographs or a more qualitative view, is prone to a personally biased selection and evaluation. Furthermore, the journals are of particular importance as they are increasingly subjected to standardised measurements in which internationality is taken as a token for quality. In 2007, the European Reference Index for the Humanities (ERIH) produced a graded list of journals of the history and philosophy of science (including the history of medicine) in order to 'identify excellence in humanities scholarship'. ${ }^{11}$ This initiative has provoked a joint response from the editors of a great number of history, science, technology and medicine journals, who consider it a 'dangerous and misguided exercise'. ${ }^{12}$ Our survey suggests indeed that a simple ranking of journals according to their alleged internationality is dangerous as it favours certain aspects of internationality and devalues others. The whole group of medical history journals shows, in fact, a lack of internationality on various levels and lacks a sense of coherence. Journals run the risk of losing their function, both as international platforms of discourse on general and theoretical issues and major trends in historiography, and as international collections of papers representing and shaping the developments in the field at large and in its various sub-disciplines. Journal editors should therefore force their authors to write a more international report, and authors should be encouraged to submit papers of international interest and from a more general, transnational and methodological point of view.

\section{The Journals}

We have selected seventeen journals (Table 1) based on the criteria that the journal had to:

- be published in one of the major western languages: English, French, German, Italian, Spanish or Dutch (which excluded journals like the Finnish Hippokrates or the Japanese Nihon Ishigaku Zasshi),

\footnotetext{
${ }^{10}$ Olga Amsterdamska and Anja Hiddinga, 'Trading Zones or Citadels? Professionalization and Intellectual Change in the History of Medicine', in Huisman and Warner, op. cit. (note 7), 237-61.

${ }^{11}<$ http://www.esf.org/research-areas/humanities/ erih-european-reference-index-for-the-humanities/ erih-initial-lists.html>, accessed 15 April 2011.
}

\author{
${ }^{12}$ See, for example, 'Journals Under Threat: A \\ Joint Response from History of Science, Technology \\ and Medicine Editors', Medical History, 53 (2009), \\ $1-4$.
}




\section{Table 1}

List of 17 selected medical history journals

\begin{tabular}{|c|c|c|c|c|c|}
\hline Abbreviation & Title & Country & Foundation & $\begin{array}{l}\text { Papers } \\
\text { per } \\
\text { year }\end{array}$ & $\begin{array}{l}\text { Pages } \\
\text { per year }\end{array}$ \\
\hline Sudh. Arch. & $\begin{array}{l}\text { Sudhoffs Archiv. Zeitschrift für } \\
\text { Wissenschaftsgeschichte }\end{array}$ & Germany & 1907 & 12 & 220 \\
\hline $\begin{array}{l}\text { Bull. Hist. } \\
\text { Med. }\end{array}$ & Bulletin of the History of Medicine & USA & 1933 & 21 & 540 \\
\hline Gesnerus & $\begin{array}{l}\text { Gesnerus. Swiss Journal for the } \\
\text { History of Medicine and Sciences }\end{array}$ & Switzerland & 1943 & 13 & 220 \\
\hline J. Hist. Med. & $\begin{array}{l}\text { Journal of the History of Medicine } \\
\text { and Allied Sciences }\end{array}$ & USA & 1946 & 15 & 400 \\
\hline Asclepio & $\begin{array}{l}\text { Asclepio. Revista de Historia de la } \\
\text { Medicina e Cienca }\end{array}$ & Spain & 1949 & 21 & 530 \\
\hline Med. Hist. & Medical History & UK & 1957 & 22 & 400 \\
\hline Med. Sec. & Medicina nei Secoli. Arte e Scienza & Italy & 1964 & 35 & 530 \\
\hline $\begin{array}{l}\text { Medizinhist. } \\
\text { J. }\end{array}$ & Medizinhistorisches Journal & Germany & 1966 & 11 & 300 \\
\hline $\begin{array}{l}\text { Hist. Sc. } \\
\text { Méd. }\end{array}$ & Histoire des Sciences Médicales & France & 1967 & 33 & 430 \\
\hline Gewina & $\begin{array}{l}\text { Gewina: Tijdschrift voor de } \\
\text { Geschiedenis der Geneeskunde, } \\
\text { Natuurwetenschappen, Wiskunde } \\
\text { en Techniek }\end{array}$ & Netherlands & 1978 & 15 & 230 \\
\hline Dynamis & $\begin{array}{l}\text { Dynamis. Acta Hispanica ad } \\
\text { Medicinae Scientiarumque Historiam } \\
\text { Illustrandam }\end{array}$ & Spain & 1981 & 16 & 450 \\
\hline $\begin{array}{l}\text { Med. Ges. } \\
\text { Gesch. }\end{array}$ & Medizin, Gesellschaft und Geschichte & Germany & 1982 & 8 & 260 \\
\hline Can. Bull. & Canadian Bulletin of Medical History & Canada & 1984 & 15 & 350 \\
\hline $\begin{array}{l}\text { Soc. Hist. } \\
\text { Med. }\end{array}$ & Social History of Medicine & UK & 1988 & 22 & 450 \\
\hline Vesalius & $\begin{array}{l}\text { Vesalius: Official Journal of the } \\
\text { International Society for the History } \\
\text { of Medicine }\end{array}$ & $\begin{array}{l}\text { France, } \\
\mathrm{UK}^{* *}\end{array}$ & 1995 & 14 & 100 \\
\hline $\begin{array}{l}\text { Health \& } \\
\text { Hist. }\end{array}$ & $\begin{array}{l}\text { Health and History: Bulletin of the } \\
\text { Australian Society of the History } \\
\text { of Medicine }\end{array}$ & Australia & 1998 & 11 & 240 \\
\hline $\begin{array}{l}\text { Med. e } \\
\text { Storia }\end{array}$ & $\begin{array}{l}\text { Medicina e Storia: Rivista di } \\
\text { Storia della Medicina e della Sanità }\end{array}$ & Italy & 2001 & 7 & 150 \\
\hline
\end{tabular}

*only papers (excluding notes and reviews)

${ }^{* *}$ residence of the editors 


\section{Parochialism or Self-Consciousness?}

- lay claim to a certain degree of internationality and thus include English abstracts (which excluded the Spanish Medicina e Historia or the German Würzburger Medizinhistorische Mitteilungen),

- devote the majority of its articles to the history of medicine (which excluded journals like Isis, Nuncius, NTM or Early Science and Medicine),

- treat a great variety of subjects (which included Social History of Medicine but excluded the more narrowly orientated Journal of Medical Biography or Historia Hospitalium). ${ }^{13}$

\section{Organisation and Editorial Policy}

Many of the journals are edited on behalf of a national society (Bulletin of the History of Medicine, Canadian Bulletin of Medical History, Gesnerus, Gewina, Health \& History, Histoire des Sciences Médicales), or international society (Social History of Medicine, Vesalius), or by a scientific institution (Asclepio, ${ }^{14}$ Dynamis, ${ }^{15}$ Medical History, ${ }^{16}$ Medicina nei Secoli, ${ }^{17}$ Medizin, Gesellschaft und Geschichte, ${ }^{18}$ Medizinhistorisches Jour$\left.n a l^{19}\right)$. Only three (Journal of the History of Medicine and Allied Sciences, Medicina e Storia, Sudhoffs Archiv) have no dominant institutional affiliation.

The journals are mostly run by an office of one to three main editors and a national group of supporting editors responsible for the general direction of the periodical; a well-chosen group of ten-to-thirty international scientists forms the advisory committee that serves as a pool of peer reviewers and adds credibility to the project. Three journals have no international advisers (Bulletin of the History of Medicine, Histoire des Sciences Médicales Journal of the History of Medicine and Allied Sciences), one is directed solely by a group of five editors (Sudhoffs Archiv) and one by a single editor (Medizin, Gesellschaft und Geschichte).

All journals, except for three, follow a peer-review practice that includes reviewing by one-to-three persons from the editorial board and by one-to-four external experts. ${ }^{20}$ In the case of Sudhoffs Archiv and Vesalius, submitted papers are only reviewed by members of the board. Histoire des Sciences Médicales has no proper review practice as it publishes mainly the lectures from the French society's annual meetings.

We have asked the journals to give us the number of annually submitted manuscripts. From their answers we may conclude that the continental, Canadian and Australian journals receive fifteen to thirty papers ${ }^{21}$, the two British journals receive fifty, and the two American journals roughly eighty papers per year. If we take into account the number of

\footnotetext{
${ }^{13}$ A comprehensive - although not complete - list of medical history journals is given in Eckart and Jütte, op. cit. (note 7), 355-8.

${ }^{14}$ Spanish National Research Council.

${ }^{15}$ Universities of Granada, Barcelona and Elche.

${ }^{16}$ At the time of writing, published by The Wellcome Trust Centre for the History of Medicine at UCL, and from 2006 as the official journal of the European Association for the History of Medicine and Health.
}

\footnotetext{
${ }^{17}$ Department of Experimental Medicine and Pathology, University 'La Sapienza', Rome.

${ }^{18}$ Institute for the History of Medicine of the Robert Bosch Foundation, Stuttgart.

${ }^{19}$ Mainz Academy of Sciences and Literature, Committee for the History of Medicine and Sciences.

${ }^{20}$ Information based on enquiry and official statements.

${ }^{21}$ Except Medicina nei Secoli with forty-to-fifty, mostly invited, papers.
} 


\section{Hubert Steinke and Yves Lang}

published articles, we may presume that the first group accepts approximately half, the second a third and the last a quarter of the papers submitted to their editors. These figures have, however, to be judged with some caution, as five journals have not answered our enquiry, and as all editors except one had to rely on estimates based on personal, potentially biased recollection.

\section{Language}

An English summary seems to be considered a mark of internationality. The Medizinhistorisches Journal, which introduced English summaries only in 2002, did so explicitly 'in order to find more international reception'. ${ }^{22}$ Some journals were eager to display this sign of internationality even if they - or their authors - lacked the necessary command of English and thus published texts filled with grammatical errors. Interestingly, over the ten-year period, this effort towards global spread did not lead to an increased number of English articles. All journals maintain their original distribution of languages. There are monolingual journals in English (Bulletin of the History of Medicine, Medical History, Journal of the History of Medicine and Allied Sciences, Social History of Medicine, Health \& History), French (Histoire des Sciences Médicales) and Dutch (Gewina). The others are bi- or trilingual periodicals with the native tongue dominating up to $90 \%$ (Asclepio, Sudhoffs Archiv, Medizinhistorisches Journal: 10\% English), 80\% (Medicina e Storia: 10\% English, 10\% French; Canadian Bulletin of Medical History: 80\% English, 20\% French) or 70\% (Dynamis: 30\% English; Medicina nei Secoli: 20\% English, 10\% French). The two linguistically most-balanced journals are Vesalius with $63 \%$ English, $37 \%$ French and Gesnerus with 45\% German, 40\% French and 15\% English articles.

\section{Authors: Professionalisation and Nationality}

Amsterdamska and Hiddinga have observed a strong gradual shift towards professionalisation from 1960 to 2000, which is visible in the decrease of authors with an MD (from $52 \%$ to $13 \%$ ) and an increase of those with a $\mathrm{PhD}$ (from $29 \%$ to $77 \%$ ). ${ }^{23}$ As it was difficult to establish the academic degree in many cases, we focused on the institutional affiliation of the authors. Our survey confirms a generally high level of professionalisation. In most journals, roughly $90 \%$ of the authors were affiliated to a university or other academic institution. Two journals lack such a tight attachment to academia: Vesalius with 35\% non-affiliated authors, and Histoire des Sciences Médicales with an uncertain but presumably even higher figure. ${ }^{24}$ Gewina has also roughly $25 \%$ 'private' authors, which reflects the Dutch society's intention to provide a platform for amateurs, although the journal is edited by professionals and thus mainly publishes articles from historians. ${ }^{25}$ Another strong indicator of professionalisation is the author's academic department. In

\footnotetext{
${ }^{22}$ Medizinhistorisches Journal, 37 (2002), 4. All other journals introduced them before 1997.

${ }^{23}$ Amsterdamska and Hiddinga, op. cit. (note 10).

${ }^{24}$ Institutional affiliation is rarely noted in this journal and was verified only for a selected period.
}

\footnotetext{
${ }^{25}$ A tension between the society's amateurs and the professional editorial board is observed by Bert Theunissen, 'Journals of the History of Science in the Netherlands', in Marco Beretta, Claudio Pogliano and Pietro Redondi (eds), Journals and History of Science (Firenze: Olschki, 1998),197-210.
} 


\section{Parochialism or Self-Consciousness?}

fourteen journals, 70-90\% of the authors are affiliated to a humanities department or an institute of history of medicine or sciences, exceptions being again Vesalius $(50 \%)$ and the French journal, Histoire des Sciences Médicales, for which we must presume a strong dominance of the medical department as its authors are chiefly MDs. Medicina nei Secoli publishes somewhat more papers from the departments of medicine and natural sciences (34\%) than the other professional journals.

The institutionalisation of medical historical research in different countries is mirrored in the relationship between authors from medical and general history (or humanities) institutes. In the German and Swiss journals, members of institutes of the history of medicine or science account for two-thirds of all articles written by professionals, in the Italian and Spanish for half, in the American and British as follows: 40\% (Medical History), 30\% (Bulletin of the History of Medicine), 25\% (Journal of the History of Medicine and Allied Sciences, Social History of Medicine); in the Canadian and Dutch (Canadian Bulletin of Medical History and Gewina respectively) 20\%; and in the Australian journal (Health and History) $10 \%$.

Authors publish predominantly in journals of their mother country and language (Table 2). Usually, 65 to $85 \%$ of their articles appear in the local periodical. Spanish, Italian and Dutch authors - who cannot publish in their own language abroad - show an even higher inclination to stick to their journal at home. English-speaking scholars are somewhat more prone to publish in foreign journals, but their selection is usually limited to monolingual British periodicals or such with a strong dominance of English articles.

As a reflection of this preference of national and native-language publication, the journals appear mostly as a platform for research done at home (Table 3). ${ }^{26}$ In the case of the Dutch, French and one of the German journals, almost all, or over $90 \%$ of the articles are written by authors residing in the journal's country. For most other journals, this applies to $60-80 \%$ of the papers. Usually two to three countries account for $80 \%$ or more of the production. In the case of the American journals, for instance, American, British and Canadian authors furnish roughly $90 \%$ of the content. The only truly international journal is Vesalius: seven different countries are responsible for $70 \%$ of the papers, the rest is written by authors from twenty-two different countries.

\section{Subjects}

The history of one's own country is by far the most important subject. In $53 \%$ of their papers, authors focus on their mother country. ${ }^{27}$ They do so primarily in their national journals in which $50 \%$ of the papers deal with domestic subjects (Table 4). Roughly $20 \%$ of the articles have an international perspective, that is, discuss a topic globally, independent of local circumstances or by treating at least three countries. ${ }^{28}$ Another $20 \%$ concentrate on one or two countries that are not those of the journal; approximately $10 \%$ deal with non-Western countries or regions (Asia, Africa, South and Central

\footnotetext{
${ }^{26}$ Figures are based not on nationality but on the author's residence.

${ }^{27}$ If a paper deals with two countries, half of it has been ascribed to each country; if it deals with
}

three countries it has been counted as an international article.

${ }^{28}$ Articles on the prehistorical and classical world are generally considered international. 
Table 2

Publishing in national and foreign medical history journals, 1997-2006

\begin{tabular}{lll}
\hline $\begin{array}{l}\text { Authors } \\
\text { residing in }\end{array}$ & $\begin{array}{l}\text { \% of publications } \\
\text { in mother country }\end{array}$ & \% of publications in other countries \\
\hline Spain & 94 & I (2), UK (2) \\
Italy & 92 & E (2), F (2), UK (2) \\
Netherlands & 85 & UK (6), D (4), USA (2) \\
France & 84 & I (6), E (4), UK (3) \\
Germany & 77 & CH (9), UK (6), I (4), USA (2) \\
Switzerland & 71 & I (12), D (6), CDN (4), USA (3) \\
UK & 70 & USA (11), I (5), D (4), E (4) \\
Australia & 65 & UK (22), USA (6), CDN (3) \\
USA & 65 & UK (14), I (6), CDN (5), E (5), AUS (2) \\
Canada & 60 & USA (17), UK (15), E (2), I (2) \\
\hline
\end{tabular}

Table 3

Native and foreign authors publishing in medical history journals, 1997-2006

\begin{tabular}{llll}
\hline Journal & \multicolumn{2}{l}{ \% of native authors } & \% of foreign authors from \\
\hline Gewina & Netherlands & 96 & \\
Hist. Sci. Méd. & France & 91 & \\
Medizinhist. J. & Germany & 88 & UK (5), I (2) \\
Sudh. Arch. & Germany & 79 & UK (5), USA (2), A (2) \\
Can. Bull. & Canada & 76 & USA (11), UK (3), AUS (3), CH (3), F (2) \\
J. Hist. Med. & USA & 73 & UK (10), CDN (8), AUS (3) \\
Med. Sec. & Italy & 73 & F (6), USA (5), UK (4), D (3), CH (2), E (2) \\
Health \& Hist. & Australia & 71 & NZ (15), USA (8), UK (4) \\
Asclepio & Spain & 70 & MEX (5), F (5), ARG (4), BRA (4), UK (4) \\
Med. Ges. Gesch. & Germany & 65 & UK (10), NL (6), CH (5) \\
Med. e Storia & Italy & 65 & UK (14), CH (9), F (5) \\
Bull. Hist. Med. & USA & 64 & UK (14), CDN (10), AUS (2), D (2) \\
Med. Hist. & UK & 61 & USA (9), D (6), CDN (5), NL (4), AUS (3) \\
Dynamis & Spain & 58 & USA (10), GB (8), MEX (4), CDN (3), D (3) \\
Soc. Hist. Med. & UK & 56 & USA (13), AUS (9), CAN (8), D (3), F (3) \\
Gesnerus & Switzerland & 51 & D (21), F (8), UK (8), AUS (2), CDN (2), USA (2) \\
Vesalius & France / UK & 37 & I (9), ISR (7), USA (7), B (6), CDN (5) \\
\hline
\end{tabular}

America). As a result of the author's strong interest in national history, journals with a high percentage of native authors usually also have a high percentage of articles dealing with native topics.

More than two-thirds of all articles concern the nineteenth and twentieth centuries (Table 5). Journals with a predominant interest in the modern period tend to be less 
Parochialism or Self-Consciousness?

Table 4

Geographic focus in medical history journals, 1997-2006 (in \%)

\begin{tabular}{lllll}
\hline Journal & mother country & other countries & inter-national & non-western \\
\hline Gewina & 74 & 6 & 18 & 2 \\
Hist. Sci. Méd. & 70 & 5 & 18 & 7 \\
Health \& Hist. & 69 & 5 & 17 & 9 \\
Can. Bull. & 64 & 19 & 12 & 5 \\
Medizinhist. J. & 62 & 14 & 21 & 3 \\
Med. e Storia & 50 & 22 & 28 & 0 \\
Med. Sec. & 50 & 31 & 12 & 7 \\
Asclepio & 49 & 9 & 19 & 23 \\
Dynamis & 48 & 14 & 18 & 20 \\
Soc. Hist. Med. & 46 & 23 & 15 & 16 \\
Sudh. Arch. & 45 & 21 & 26 & 8 \\
Med. Ges. Gesch. & 43 & 21 & 32 & 4 \\
Bull. Hist. Med. & 41 & 26 & 25 & 8 \\
J. Hist. Med. & 41 & 34 & 16 & 9 \\
Med. Hist. & 41 & 12 & 36 & 11 \\
Vesalius & 30 & 29 & 26 & 15 \\
Gesnerus & 29 & 30 & 40 & 1 \\
Average & $50(50)$ & $19(20)$ & $22(23)$ & 9 (7)
\end{tabular}

*according to the number of journals (to the total number of articles)

international in their geographic focus than others ( $c f$. Table 4) which suggests that the last two centuries are discussed more from a national perspective than the earlier periods. Early modern, and especially mediaeval and ancient history, are rarely treated in history of medicine journals; this holds true particularly for the American, Canadian and Australian periodicals. This lack of attention seems to have fostered - and presumably is also partly the result of - the foundation of the British journal Early Science and Medicine in 1996.

Amsterdamska and Hiddinga have shown a decrease in biographical articles (from $38 \%$ to $12 \%$ ) and an increase in those dealing with profession and practice (from 26 to $36 \%$ ) and public health (from $3 \%$ to $10 \%$ ) in the decades up to $2000 .{ }^{29}$ On the whole, our survey confirms this development, although some of the journals display quite a different distribution of topics. ${ }^{30}$ Vesalius and Histoire des Sciences Médicales still hold to the traditional focus on biography $(35-40 \%)$ with relatively few papers devoted to profession and practice (5-15\%). Science is another main area of these two journals, along with Gesnerus, Gewina, Medizinhistorisches Journal and Sudhoffs Archiv, and both of the Spanish journals (30-50\%). This dominance of science topics - which stands in contrast to their relatively small significance in the American and British journals (15\%) - is

\footnotetext{
${ }^{29}$ Amsterdamska and Hiddinga, op. cit. (note 10), $\quad{ }^{30}$ We have not analysed the whole period of ten 244-6. years but only $2000-2001$.
} 
Table 5

Focus on periods in medical history journals, 1997-2006 (in \%)

\begin{tabular}{llllll}
\hline Journal & $\begin{array}{l}\text { 19th and 20th } \\
\text { century }\end{array}$ & early modern & medieval & ancient and pre-historical & none \\
\hline Health \& Hist. & 98 & 2 & 0 & 0 & 0 \\
Can. Bull. & 90 & 8 & 2 & 0 & 0 \\
J. Hist. Med. & 82 & 12 & 2 & 3 & 1 \\
Med. Sec. & 81 & 10 & 4 & 4 & 1 \\
Soc. Hist. Med. & 79 & 13 & 7 & 1 & 0 \\
Bull. Hist. Med. & 75 & 12 & 4 & 2 & 7 \\
Gewina & 75 & 19 & 4 & 1 & 1 \\
Hist. Sci. Méd. & 71 & 20 & 2 & 5 & 2 \\
Med. e Storia & 70 & 22 & 1 & 3 & 4 \\
Asclepio & 69 & 24 & 3 & 1 & 3 \\
Medizinhist. J. & 64 & 19 & 5 & 12 & 3 \\
Med. Ges. Gesch. & 61 & 31 & 2 & 3 & 1 \\
Gesnerus & 60 & 34 & 1 & 4 & 7 \\
Dynamis & 56 & 25 & 18 & 1 & 3 \\
Med. Hist. & 44 & 23 & 12 & 14 & 0 \\
Vesalius & 42 & 36 & 7 & 12 & 2 \\
Sudh. Arch. & 40 & 26 & 22 & 12 & \\
Average & 68 & 20 & 5.5 & 4.5 & \\
\hline
\end{tabular}

*according to the number of journals and the total number of articles (identical figures)

partly due to the fact that several of these periodicals are not only devoted to the history of medicine but also to science (as their titles make clear).

\section{Citations}

We counted 3,027 mutual citations within the seventeen selected journals, 1,158 of which are self-citations (Table 6). These numbers include citations of articles published prior to 1997, which means that they favour older journals. Moreover, voluminous journals tend to receive more citations than small ones. The figures have thus to be interpreted with caution and cannot serve as a simple tool for the establishment of a ranking of citations. A 75-year-old journal, like the Bulletin with an annual size of some 530 pages of papers ( $c f$. Table 1), is necessarily more often quoted than a 240page journal, such as Health \& History founded in 1998. Nevertheless, bearing in mind these biases, the table can help us identify some general characteristics and trends of the spread and reception of journal literature in the history of medicine.

The number of citations of other journals varies from 0.5 to 6.3 per 100 pages. Sudhoffs Archiv hardly ever quotes a history of medicine journal. Gewina and Histoire des Sciences Médicales are periodicals with a strong self-referential character: they cite mainly themselves and rarely another journal. The Bulletin quotes itself somewhat more often than all the other journals together. The rest of the journals show a 


\section{Parochialism or Self-Consciousness?}

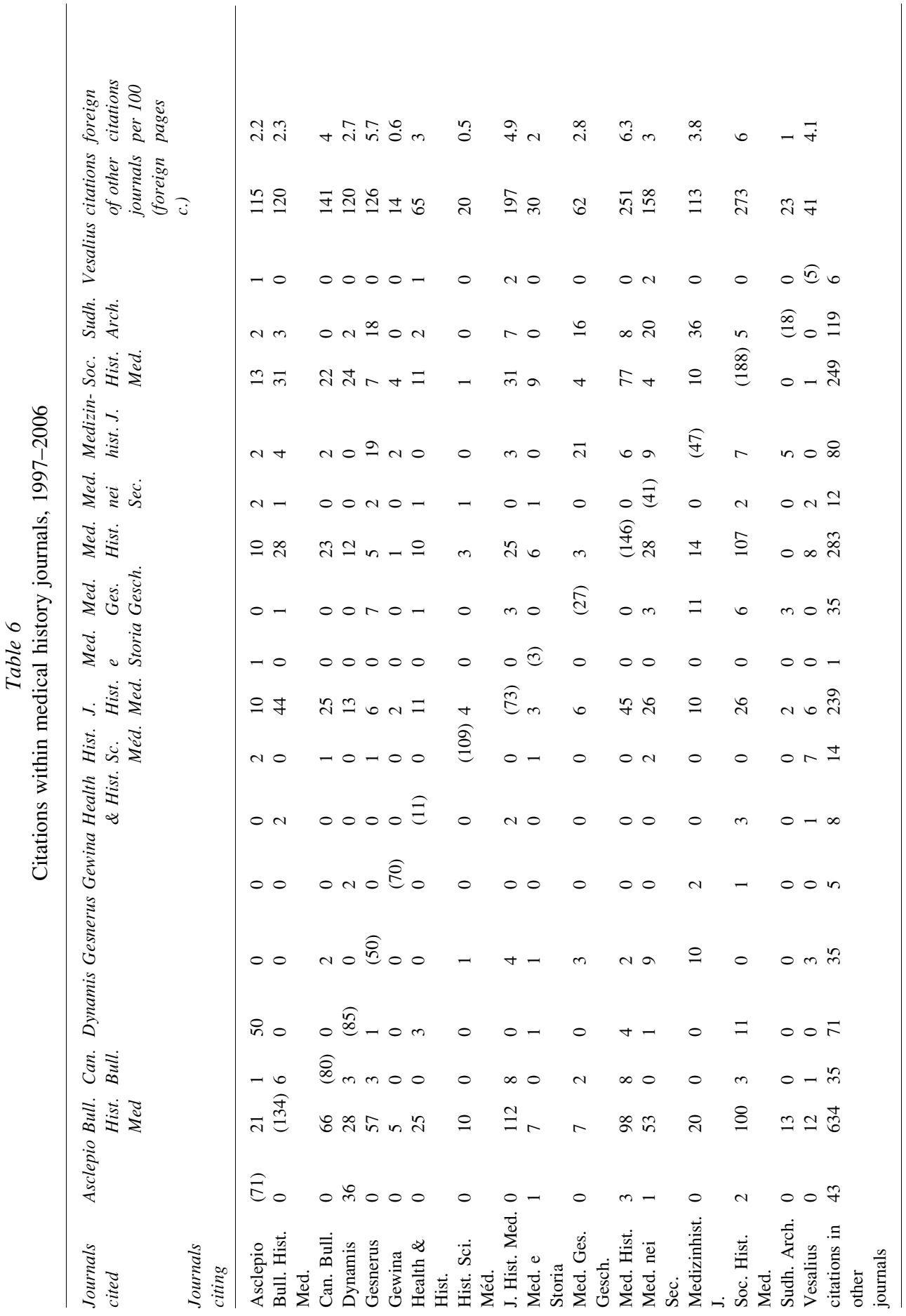




\section{Hubert Steinke and Yves Lang}

predominance of foreign references, the average being $60 \%$ of foreign and $40 \%$ of selfcitations. Health \& History and Medicina e Storia have a lower percentage of selfreference because of their late foundation.

The table shows a strong dominance of the four American and British journals which are quoted much more often than all other periodicals and thus are responsible for $75 \%$ of all citations (bottom row: citations in other journals). They are taken notice of internationally but they only rarely mention articles from other history of medicine journals: 91\% of their citations are made within the Anglo-American foursome. Two other, though much less dominating, groupings with a heightened amount of mutual references, are those of the two Spanish, and that of the four German/Swiss journals. Besides their own group they cite - as all journals - predominantly the Anglo-American periodicals. This is particularly true of the Canadian and the Australian journals, which quote almost only the American and British journals.

\section{Different aspects of internationality}

Our survey of 2,941 articles suggests that there is only a weak bond between the history of medicine journals. The average article is twenty pages and contains one single reference to a medical history periodical, in $40 \%$ of the cases, to the journal in which it is published. At first glance, this lack of coherence seems mainly to be due to an inherent national character of most of the journals that are usually run by a national society or a nationally rooted institution. The most common case is a paper written by a local author in his own language on a national subject regarding the nineteenth or twentieth century. The question remains, however, whether this lack of internationality has to be deplored and how it relates to quality. We have to distinguish between different aspects of internationality: topics, citations and authors.

Treating a national topic does not necessarily imply that it is discussed exclusively from a national point of view. Historiography - and also medical historiography - in the last few decades has increasingly adopted comparative, transnational and global approaches. Some historians have, however, expressed concern that this innovative method 'is in danger of becoming merely a buzzword among historians, more a label than a practice, more expansive in its meaning than precise in its application. ${ }^{31}$ Our citation figures indeed suggest that transnational history is not very well established in medical history - and especially Anglo-American - journals: they either discuss national topics mainly from a national perspective or - if they adopt a transnational approach they tend to neglect research conducted in other countries and languages. In this respect (and presuming that all major European countries make significant contributions to the history of medicine), lack of internationality is, in fact, a sign of lack of quality.

The dominance of national, local authors is presumably not a peculiarity of history of medicine journals but applies to many branches of the humanities. It emerges also in a survey of history of science journals from 1998, although it is discussed only cursorily. ${ }^{32}$

\footnotetext{
31 'AHR Conversation: On Transnational History', The American Historical Review, 111 (2006), 1441-63: 1441.
}

\footnotetext{
${ }^{32}$ Beretta, op. cit. (note 25).
} 


\section{Parochialism or Self-Consciousness?}

Isis, generally considered the leading periodical of the discipline, is described as a journal in which - despite a very international period in the 1920s and 1930s and despite its subtitle 'an international review' - almost $90 \%$ of the articles come from the USA, Canada and the United Kingdom. This means that it is "not the most obvious destiny for work emerging in continental Europe'. ${ }^{33}$ The situation in history of medicine appears to be quite similar; the question remains why.

Part of the answer seems to lie in the existence of different cultures of medical historiography. According to Amsterdamska and Hiddinga, there is a small overlap of shared discourses between the four Anglo-American journals that 'suggests a certain social, and perhaps also an intellectual, dispersion in the field. It is as if each of those journals had its own distinct culture'. ${ }^{34}$ If this is the case, our survey implies that the cultural diversity between the Anglo-American and the other periodicals is even greater. The larger space allocated to early modern and science topics in the continental European journals seems to reveal diverging emphases in the conception of medical historiography. Even journals with a seemingly identical focus, such as Social History of Medicine and Medizin, Gesellschaft und Geschichte, appear to follow a different approach. As Karl-Heinz Leven points out, the British one intends to be an interdisciplinary journal whereas its German sister considers 'Sozialgeschichte' as a general key to history as a whole. ${ }^{35}$ Our citation table suggests that the overlap between these two journals is in fact not very high.

Nevertheless, in view of the global spread of various 'turns' in (medical) historiography and the world-wide prosperity of medico-historical research, one remains uncertain whether the journals really represent different (national) historiographical cultures, or whether we are just observing a postmodern loosening of ties enforced by a lack of language skills. Certainly, the journals have - besides their national focus - different areas of strength that determine their specific character, but these characteristics do not combine into a well-perceived and proper 'culture', as in the times of Sudhoff and Sigerist. If such a specific 'culture' were visible, a successful model could be emulated. It is not, however, evident in what sense a journal like the Bulletin - by far the most-often cited periodical - could serve as a paradigmatic model to be appropriated in a process of 'cultural transfer'. ${ }^{36}$

\section{The Changing Role of Journals}

Amsterdamska and Hiddinga have assumed that history of medicine journals mirror the state of the discipline and that the lack of intellectual exchange might be due to the fact that medical professionals remain a vital part of the audience for the history of

\footnotetext{
${ }^{33}$ Robert Fox, 'Sartonian Values in a Changing World: The Case of Isis', in Beretta, ibid., 119-30: 128 . 252.

${ }^{34}$ Amsterdamska and Hiddinga, op. cit. (note 10),

${ }^{35}$ Karl-Heinz Leven, "'Raising the Flag of this Science": Journals of Medical History from "Janus" to the Twentieth Century', in Beretta, op. cit. (note 25), 31-56: 53.
} 


\section{Hubert Steinke and Yves Lang}

medicine. ${ }^{37}$ We think that our survey should rather prompt us to ask for the status of the journals within the discipline. They seem no longer to represent or even shape the developments in the various sub-disciplines. Increasing specialisation and the need to obtain research funding has changed the role of general medical history journals. ${ }^{38}$ Scholars have to conceive and maintain well-defined research programmes in order to succeed professionally. They define some few areas of expertise and are expected to organise or to attend international symposia dealing with these subjects. The results of these meetings are international collections of revised conference papers which draw the outline of actual and future research. The great advantage of these symposia and collections is that they confront the authors with different approaches and cultures and force them to take into account the literature from other national traditions. The collections thus overcome national boundaries and often serve as an international reference work for a specific subject. From this perspective, journals tend to lose their role as international platforms of discourse. To put it in slightly exaggerated terms, journals may become the home for preliminary results of work in progress, chapters of dissertations, remains of monographs, or jigsaw pieces that did not fit into pre-defined publication projects. To some extent, they seek to prevent this development with the introduction of essay reviews and theme issues. They have, however, to pay attention not to reproduce the model of the international collections of papers. Ground-breaking work may not only appear from research programmes, but equally from marginal, unexpected sources which need a place open to everybody and to any topic and approach.

\section{Rankings}

The actual status of the journals and their importance for the history of medicine is uncertain. Given this uncertainty, the attempt to devise a ranking system is particularly bold. It does not come as a surprise that the European Reference Index for the Humanities (ERIH) has been - thanks to a protest from the editors - forced into a "process of rethinking the initial categorisation in $\mathrm{A}, \mathrm{B}$, and $\mathrm{C}$, and of remodelling it according to a division into international, national or regional. ${ }^{39}$ What such a remodelling would change, however, is unclear. The ERIH's statement that the categorisation should not be 'misperceived as a kind of ranking' is incomprehensible. It is naïve to maintain that such a division would not imply quality. What else should it imply? All the journals presented here have their national roots and readers but aim also at an international audience. Let us take just one representative example, the Spanish journal Dynamis. It publishes 70\% Spanish and 30\% English articles and has, as have all the others, English summaries. A review in 2005 stated that the history of the journal reflects the international historiographical trends and that it had aimed since its beginnings at

\footnotetext{
${ }^{37}$ Amsterdamska and Hiddinga, op. cit. (note 10), 258.

${ }^{38} C f$. Bernd Stiegler, 'Diskursstile in den Geisteswissenschaften', in Elisabeth Lack and Christoph Markschies (eds), What the Hell is Quality? Qualitätsstandards in den
}

Geisteswissenschaften, (Frankfurt: Campus, 2008), 215-29: 223-4.

39 'The European Research Index for the Humanities: A Reply to the Publishers of Journals in History of Science, Technology and Medicine', Berichte zur Wissenschaftsgeschichte, 32 (2009), 132-4: 134. 


\section{Parochialism or Self-Consciousness?}

multidisciplinary investigations, methodological plurality and an international range. ${ }^{40}$ In the initial list, this journal was ranked ' $C$ ' and would, in the new system, presumably be categorized as 'regional'. ${ }^{41}$ Such a judgment means nothing more than that the journal might perhaps aim at an international readership but has only a regional impact because the experts of ERIH have (some yet undisclosed) reasons to believe so. The other Spanish journal, Asclepio, with $90 \%$ Spanish articles, has been ranked 'B' and is presumably of greater, that is, national importance. Such verdicts expressed by experts in the field are necessarily perceived as judgments on the quality of journals that appear to be unable to meet their targets.

What, then, is an international journal? In the ERIH initial list, only the four American and British journals are ranked ' $A$ ' or, in the new terminology, 'international'. Looking at our citation figures, it is clear that the ERIH tries to rank journals exclusively according to their international reception. This is the method of evaluation in the natural and medical sciences and the creation of a list is - as ERIH states itself - only the first step towards some kind of more sophisticated bibliometric instrument, such as citation analysis. It is highly questionable that exercises like the ERIH lists will help to establish a sense of coherence in our field as they encourage scholars to publish in journals which are read internationally but are highly selective - that is, not international - in their own perception of literature and take almost no notice of non-Anglo-American journals. This would lead to fewer journals, to a further decline of internationality of journal literature at large, and thus undermine the importance of journals and add to the significance of international collections in medical historiography.

\section{Conclusions}

What should be done in order to create a certain sense of coherence in medical historiography and to re-establish journals as general platforms of discourse for the whole community of medical historians? We do not think that the establishment of English as the general language of publication would be a good strategy. In the long run, this would dissuade historians from learning other languages and lead to a decline of the understanding of foreign history. On the one hand, editors should ask their authors to perform a more international review of literature and to take into account other relevant historiographical traditions. This in no way prevents the treatment of local or national topics - which will always figure prominently in journals edited on behalf of national societies - but it puts them into an international perspective and promotes a further exchange of ideas. An active involvement of international advisory boards (which often serve as advertisement but are not regularly engaged in the review process) would help to guarantee internationality and thus quality in this respect. On the other hand, authors should be encouraged to submit papers of international interest, that is, papers which present new approaches and topics or are dealing with general, transnational, methodological, historiographical and controversial issues. They should be aware that journals are still the only publications

\footnotetext{
${ }^{40}$ José Luis Peset, 'Dynamis en sus 25 años', Dynamis, 25 (2005), 25-45.
}

\footnotetext{
${ }^{41}$ Of the seventeen journals presented here, four are ranked ' $\mathrm{A}$ ', two ' $\mathrm{B}$ ' and eight ' $\mathrm{C}$ '; three are not recorded in the ERIH initial list.
} 


\section{Hubert Steinke and Yves Lang}

read - or at least seen - by all medical historians and thus the natural and ideal platform to present new ideas and results to a wider professional audience.

\section{Acknowledgements}

For the record, it has to be noted that Hubert Steinke is a member of the editorial board of Gesnerus. We would like to thank Vincent Barras and the anonymous referees of Medical History for their useful suggestions. 